\title{
CLASSIFICATION MODEL FOR IPB STUDENT'S GRADE OF DATA MINING COURSE BASED ON THEIR ACTIVITIES IN LEARNING MANAGEMENT SYSTEM
}

\author{
Imas Sukaesih Sitanggang ${ }^{1)}$, Mutiara Santika ${ }^{1)}$, Mayanda Mega Santoni ${ }^{2)}{ }^{1)}$ Departement of \\ Computer Science, JI. Meranti Wing 20 Level V, Bogor Agricultural University, Bogor, Indonesia \\ ${ }^{2)}$ UPN Veteran Jakarta, Jl. Rs. Fatmawati, Pondok Labu, Jakarta Selatan, Indonesia, \\ imas.sitanggang@ipb.ac.id, mutiarasantika.ms@gmail.com, megasantoni@gmail.com
}

\begin{abstract}
Leaning process evaluation in higher education institutions is performed by measuring student's academic performance in completing a course. Prediction of course's grade can be done as an early warning for student's academic performance. Prediction results provide reference to evaluate the education process. There are several aspects of course evaluation, one of which is student activities on online learning management system (LMS). This study aims to build a classification model of final score of data mining course based on student's activities in LMS using the C50 decision tree algorithm. The data used are log files of LMS activities for data mining course which is offered for Bachelor students on Computer Science, Bogor Agricultural University. This study results the classification model with the accuracy of $85.71 \%$.
\end{abstract}

Keywords: data mining, decision tree, learning management system

\section{INTRODUCTION}

Data Mining (Course ID: KOM332) is one of major courses that is offered to Bachelor program of Computer Science, Bogor Agricultural University (IPB). The learning outcome of Data Mining Course is that after completing this course, students will be able to apply data processing steps and basic techniques in data mining to the realworld dataset. In order to achieve the learning outcome, this course covers several topics including introduction to data mining (topic 1), data and data exploration (topic 2), data preprocessing (topic 3), cluster analysis (topic 4), outlier detection (topic 5), classification using the decision tree algorithm (topic 6), other methods in classification (topic 7), association analysis (topic 8), other methods in association analysis (topic 9), data warehouse and OLAP (Online Analytical Processing) (topic 10), introduction to spatio-temporal data mining (topic 11), introduction to sequential pattern mining (topic 12), introduction to text and web mining (topic 13) and 
applications of data mining techniques (topic 14). In order to support face-to-face learning activities in class room and computer laboratory, Data Mining course in IPB uses e-learning system which is provided in the Bogor Agricultural University Learning Management System (IPB-LMS), https://Ims.ipb.ac.id/. IPB-LMS uses an open-source learning management system Moodle. Moodle is a learning platform written in PHP which is designed for educators, administrators and learners in managing course contents and learning activities. In addition to web-based version, IPB-LMS is also available in mobile application named Moodle Mobile that can be accessed by users using IPB access account. Based on the log activities of IPB-LMS for Data Mining course, this study calculates the number of page views since 8 November 2010 as presented in Figure 1. Data Mining course in IPB is offered in even semester in each academic year starting from February to August. High log activities are found this period as shown in Figure 2.

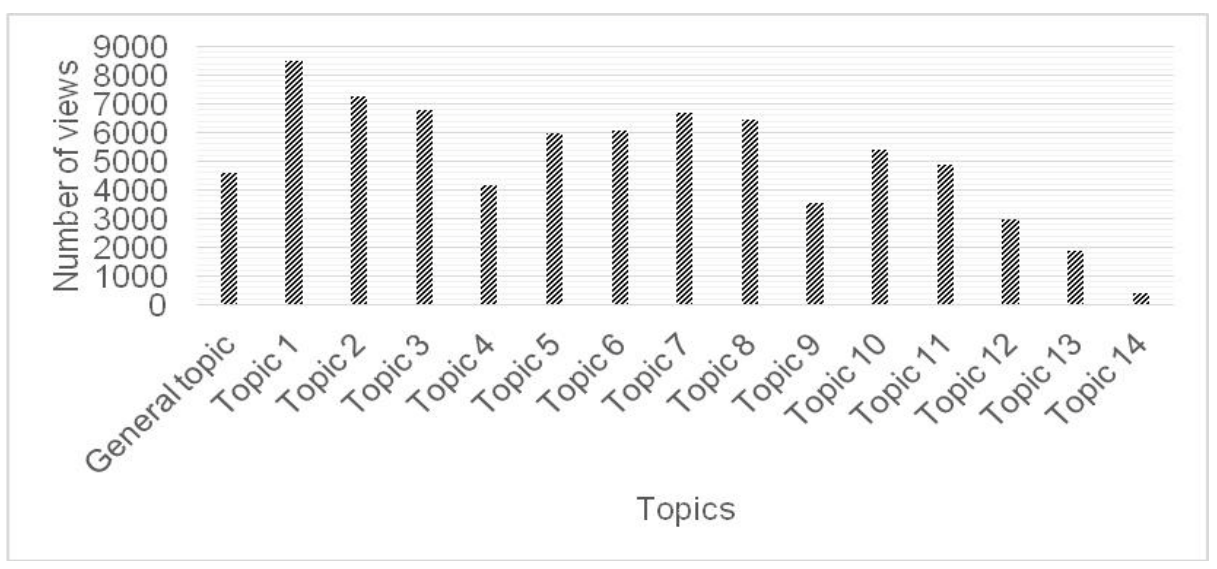

Figure 1. Number of views on IPB-LMS for Data Mining Course since 8 November 2010

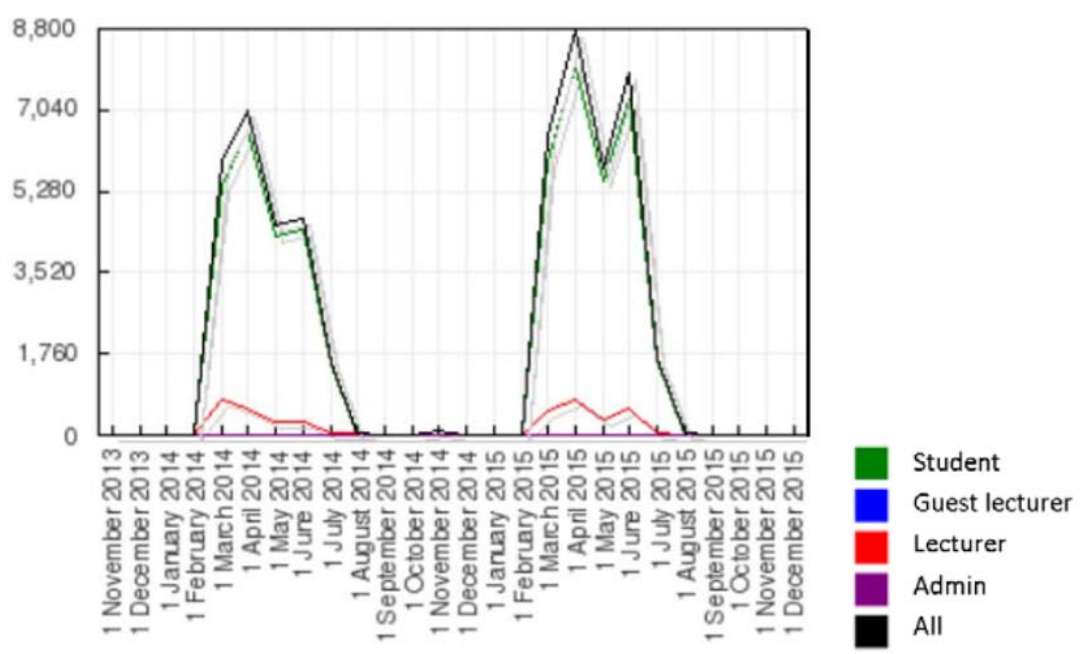

Figure 2. Number of views of IPB-LMS for Data Mining Course in the period of 2014-2015 
Currently students' performance in completing Data Mining course is measured by evaluating the grade of middle and final exams, practical works, and final project report. However, students' activities in IPB-LMS are not considered in students' performance evaluation in order to achieve the learning outcome of Data Mining course. Therefore, this study aims to analyze students' achievement in Data Mining course by involving their activities in IPB-LMS. Log files of students' activities in the academic year 2015/2016 are collected from IPB-LMS. The decision tree-based classification model is developed on the datasets containing log activities and data mining grade.

\section{LITERATURE REVIEW}

Data mining has wide applications in many sectors including higher education. Educational data mining is a growing discipline, that is implemented to discover interesting and useful information and knowledge from the data related to educational context. Basic techniques in data mining including clustering, association rule mining and classification have been applied in several studies to obtain data clusters, association rules and classification models from students-related datasets. Harwati et al (2015: 173 - 177) used the K-mean clustering algorithm to group students based on their demographic (gender, origin, GPA, grade of certain courses), and average of course attending. The result of this study is four student clusters namely: smart students (45.74), standard student (33.33\%), and 20.92\% belongs to low performance students. Buldu and Üçgün (2010: 5251-5259) applied the Apriori algorithm in association rules on data of students of Istanbul Eyup I.M.K.B. Vocational Commerce High School in order to obtain relation between the courses that the students failed. This study revealed that the students who are unsuccessful in numeral courses become unsuccessful again in numeral courses of one year after (Buldu and Üçgün, 2010: 5251-5259). Based on association rules discovered, the relation between performance of students in taking courses physic and chemistry, math, space science and astronomy, as well as basic electronics are analyzed in this study. Association rule mining approach was also applied by the study of Abdullah et al (2011: 107 - 111) to discover highly positive association rules on the dataset of students' enrolment dataset of computer science program at University Malaysia Terengganu (UMT). The results from association rules state that some students in UMT (intake 2008/2009) who have been offered in computer science program but not within their field interests (Abdullah et al, 2011: 107 - 111).

Based on the systematic review in the current literatures on the data mining techniques that have been used to predict students' performance, Shahiri et al (2015: 414 - 422) found that the classification method is frequently used in educational data mining area. The classification techniques that are highly applied by the researchers for predicting students' performance are Neural Network and Decision Tree. Kaur et al (2015: 500 - 508) identified the slow learners among 
students using a predictive data mining model by applying classification algorithms on the high school real world dataset. The classification algorithms used are Multilayer Perception, Naïve Bayes, SMO, J48 and REPTree using the Open source data mining tool WEKA. This study shows that among all classification algorithms, Multi Layer Perception performs best with $75 \%$ accuracy and F-measure of $82 \%$. The study by Ratnaningsih and Sitanggang (2016: 87-97) compared three classification methods: Naïve Bayes, Bagging, and C4.5 with the evaluation criteria stratified cross-validation, confusion matrix, ROC curve, recall, precision, and Fmeasure. The three classification algorithms were applied on the dataset of nonactive students in Indonesia Open University (IOU) for the period of 2004 to 2012. The results show that the Bagging method provided a higher accuracy than Naïve Bayes and C4.5. The accuracy of Bagging classification is $82.99 \%$, while the Naïve Bayes and $\mathrm{C} 4.5$ are $80.04 \%$ and $82.74 \%$ respectively.

In addition to datasets of academic students' performance, basic and advance data mining techniques have been used in several studies to discover new patterns on online learning datasets in order to improve the benefits of using online learning management system. Romero et al (2008: 368-384) developed a Moodle data mining tool that can be used by users to apply the main data mining techniques used, such as statistics, visualization, classification, clustering and association rule mining of Moodle data. The tool is integrated with the Moodle environment and provides a user-friendly interface to perform data preprocessing and mining tasks automatically on Moodle data. Romero et al (2009: 828-840) built a web mining tool integrated into the AHA! System to facilitate instructors to perform web mining process in e-learning and Web-based adaptive educational systems. The AHA! System is an open source general-purpose adaptive hypermedia system, which is available from the Eindhoven University of Technology. Macfadyen and Dawson (2010: 588-599) analyzed Learning Management System (LMS) tracking data by applying regression and logistic modelling. This study fiedidenti15 variables demonstrating a significant simple correlation with student final grade (Macfadyen and Dawson, 2010: 588-599). The best-fit predictive model using regression modelling shows that key variables such as total number of discussion messages posted, total number of mail messages sent, and total number of assessments completed influence the studentfinal grade (Macfadyen and Daws on, 2010: 588599). Moreover, Romero and Castro (2011: 77-88) developed a data mining tool that uses association rule mining and collaborativefiltering that can be used by instructors to get recommendations in e-learning courses improvement. The real interactions between the students and the e-learning course can be analyzed using this tool. The results are important as decisions to improve the e-learning course. Al-Twijri and Noaman (2015: 836 - 844) proposed a data mining model, named the Data Mining Admission Model (DMAM), to facilitate the proper vision of selecting the best enrolment method in Saudi universities. The DMAM consists of five subsystems Database Management System, Model Management System, and Knowledge Base which run on the real datasets. The strategic levels of higher 
institutions in Saudi universities can use the model to make decisions and regulation on students' admission.

\section{METHOD}

The data used in this research are log files of IPB-LMS activities for data mining course which is offered for Bachelor students on Computer Science, Bogor Agricultural University. Attributes selection in log files refers to the research conducted by Romero et al (2008: 368-384) that can be seen in Table 1.

Table 1. The attributes in log files of IPB-LMS

\begin{tabular}{|l|c|l|}
\hline \multicolumn{1}{|c|}{ Attribute } & Code & \multicolumn{1}{c|}{ Descriptions } \\
\hline n_assigment & V1 & $\begin{array}{l}\text { Number of assignments done by } \\
\text { students }\end{array}$ \\
\hline n_view_assigment & V2 & $\begin{array}{l}\text { Number of views of data mining } \\
\text { assignment }\end{array}$ \\
\hline n_course_view & V3 & Number of course view \\
\hline n_course_module_view & V4 & Number of course module view \\
\hline Score & V5 & Final score \\
\hline
\end{tabular}

The submission assignment page shows submission status such as grading status, due date, time remaining, last modified, file submission and submission comment that can be seen in Figure 3.

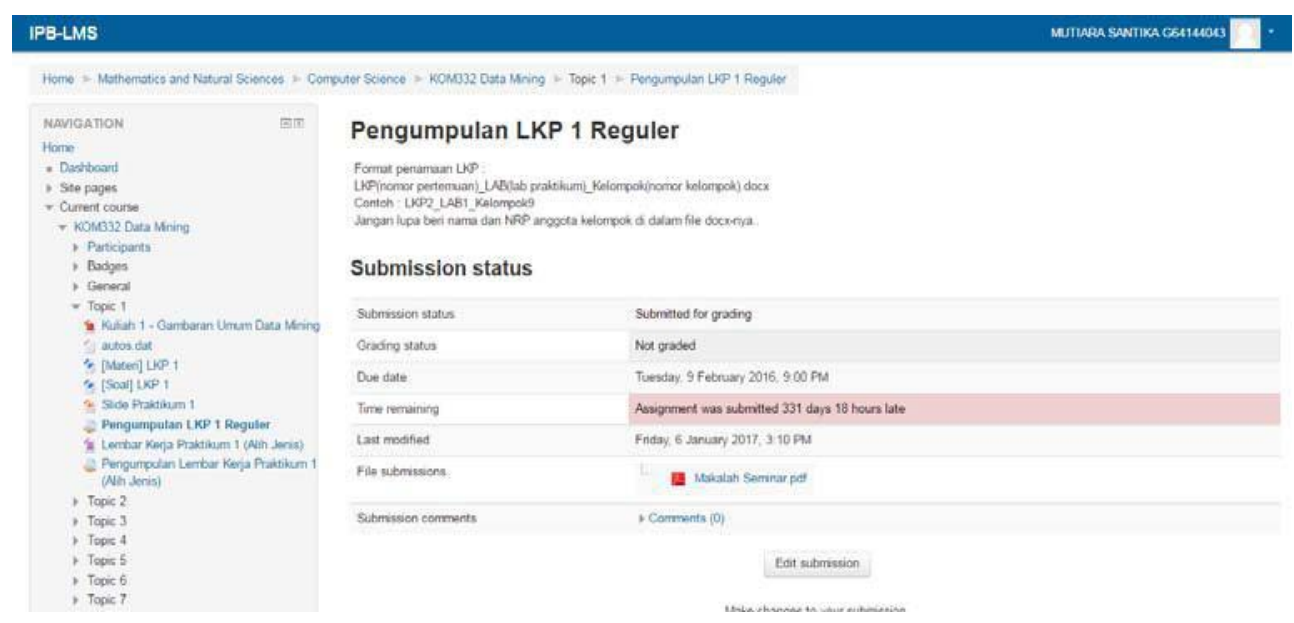

Figure 3. IPB-LMS page to upload data mining assignments

To view assignments in data mining courses, student can directly download the assignments in IPB-LMS. Figure 4 shows the IPB-LSM page to view data mining assignments. 


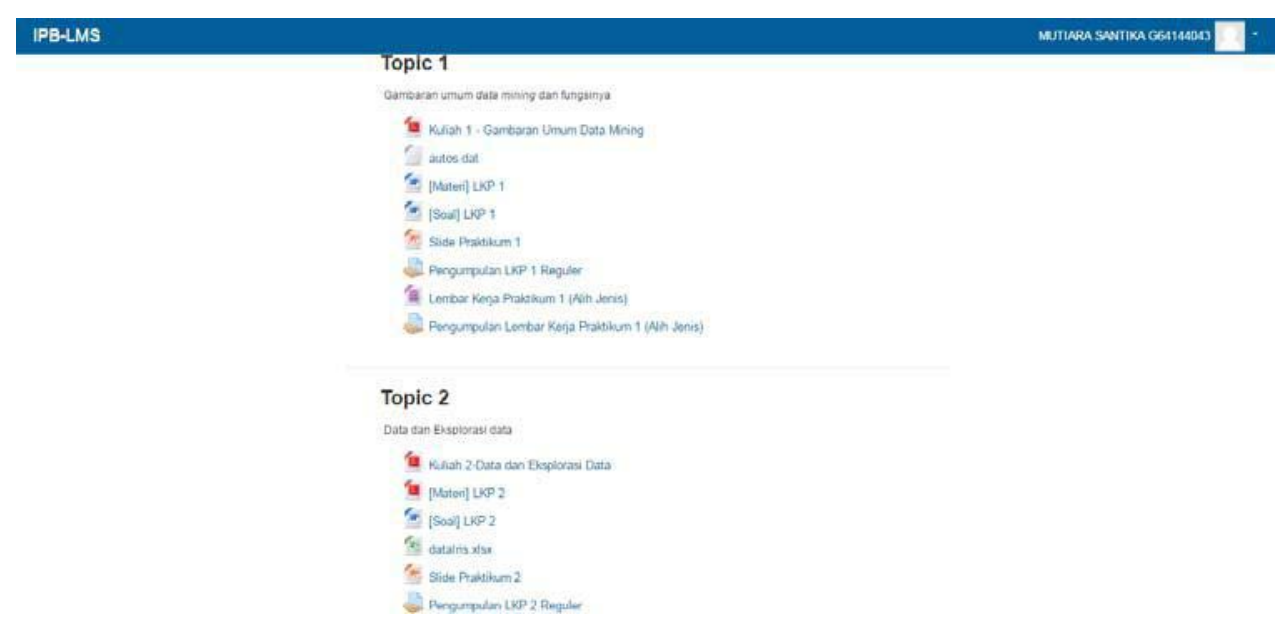

Figure 4. IPB-LSM page to view assignments in data mining course.

In this study, there are several steps including data collection, preprocessing data, data partition into training and testing datasets, modelling using the C50 decision tree algorithm, model evaluation, and analysis of the classification model. Figure 5 shows the steps of this study.

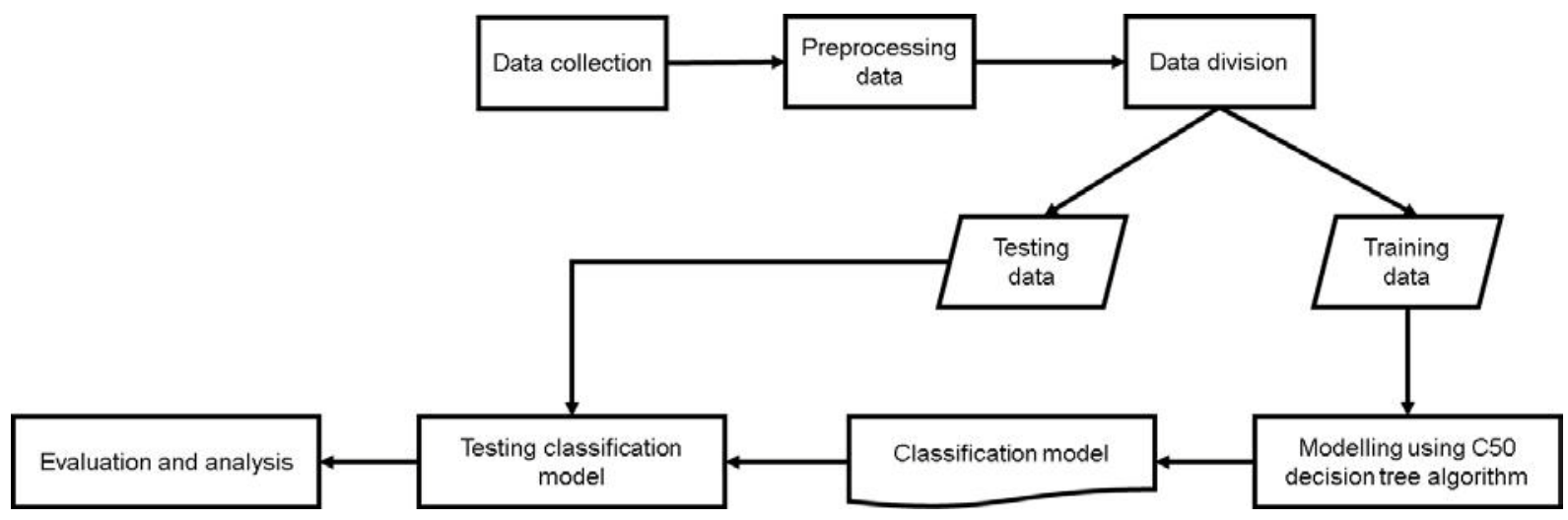

Figure 5. Research steps

The data used in this study are log files of IPB-LMS activities for 144 students who enroll the data mining course in the academic year 2015/2016. As many 37.161 log files were collected from IPB-LMS for Data Mining course. Figure 6 shows the example of data in IPB-LMS log files.

\begin{tabular}{|c|c|c|c|c|c|c|c|}
\hline Time & User full name & Affected user & Event context & Component & Event name & Descriptid Origin & IP address \\
\hline $18 \mathrm{Jul}, 09:$ & MIFTAH FAQIH G64130082 & - & Course: KOM332 Data Mil & System & Course viewed & The user I web & 172.17.71.172 \\
\hline $18 \mathrm{Jul}, 09:$ & ARFAN ANHARI G64130059 & - & URL: PALO & URL & Course module view & The user w web & 172.17.71.163 \\
\hline $23 \mathrm{Jul}, 11:$ & BINTANG JP PUTRA G64144011 & - & Course: KOM332 Data Mil & System & Course viewed & The user i web & 182.253 .163 .50 \\
\hline 22 Jul, 14: & MUHAMMAD ALVIAN SUPRIADI G & & Course: KOM332 Data Mi & System & Course viewed & The user y web & 203.123 .61 .235 \\
\hline $28 \mathrm{Jul}, 15:$ & Husnul Khotimah, S.Komp M.Kon & & Course: KOM332 Data Mil & System & Course viewed & The user y web & 172.17 .212 .2 \\
\hline $28 \mathrm{Jul}, 15:$ & Imas Sukaesih Sitanggang Sitang: & & Course: KOM332 Data Mi & System & Course viewed & The user y web & 172.17 .212 .2 \\
\hline 15 Jun, 15 & PANDU WARJAYA G64144049 & - & Course: KOM332 Data Mil & System & Course viewed & The user y web & 182.253.163.51 \\
\hline 15 Jun, 15 & JEANNETTE CLAUDYA WEYA PANT & & File: Kuliah 12 - Text \&am & File & Course module view & The user web & 103.14.18.164 \\
\hline
\end{tabular}

Figure 6. The example of data in IPB-LMS log files 
Preprocessing data is done to improve data quality so that accuracy of model increases. The preprocessing tasks include data cleaning and attribute selection. The IPB-LMS activities were obtained from the attribute event name on the IPB LMS log files. The attributes include course view, course module view, assignments view, assignments upload, and final score as decision class. The output of data preprocessing steps is a task relevant data for classification process using the decision tree algorithm.

The next step is calculating the number of each activity in the log file. Each activity is grouped into 4 groups including high (3), moderate (2), low (1) and no information (0). Table 2 shows the value range for each category of attributes.

Table 2. The value range of each attributes' category

\begin{tabular}{|l|c|c|c|c|}
\hline Category & V1 & V2 & V3 & V4 \\
\hline No information (0) & 0 & 0 & 0 & 0 \\
\hline Low (1) & $1-5$ & $1-19$ & $8-102$ & $8-68$ \\
\hline Moderate (2) & $6-9$ & $20-37$ & $103-198$ & $69-126$ \\
\hline High (3) & $10-14$ & $38-56$ & $199-293$ & $127-185$ \\
\hline
\end{tabular}

The next step is labelling of class for each student's log file. The class labels are C1 for final grade $A$ and $A B$ and $C 2$ for final grade $B$ and $B C$. There are 63 data with the class label $\mathrm{C} 1$ and 81 with the class label C2. For classification task, the data are divided into a training dataset and a testing dataset using the k-cross fold validation with $\mathrm{k}=10$. The training data are used to build decision tree model, while the testing data are used to test the decision tree model. The classification model was created using the C5.0 decision algorithm. This algorithm uses information gain in making decision trees. The classification model is created using the $\mathrm{R}$ programming language with the C50 package.

The C5.0 algorithm produces tree model and a rule-based model. A tree model has a flowchart-like tree structure. In the tree model, each internal node (non-leaf node) indicates the test on an attribute, each branch represents the results of the test, and each leaf node is a class label (Han et al, 2012). A rule-based model is a set of ifthen conditions derived from a tree model. C5.0 has been designed to analyze substantial databases containing thousands to millions of records and tens to hundreds of numeric, time, date, or nominal fields (Rulequest Research, 2018). The C5.0 is implemented based on the decision tree algorithm (Han et al, 2012): 


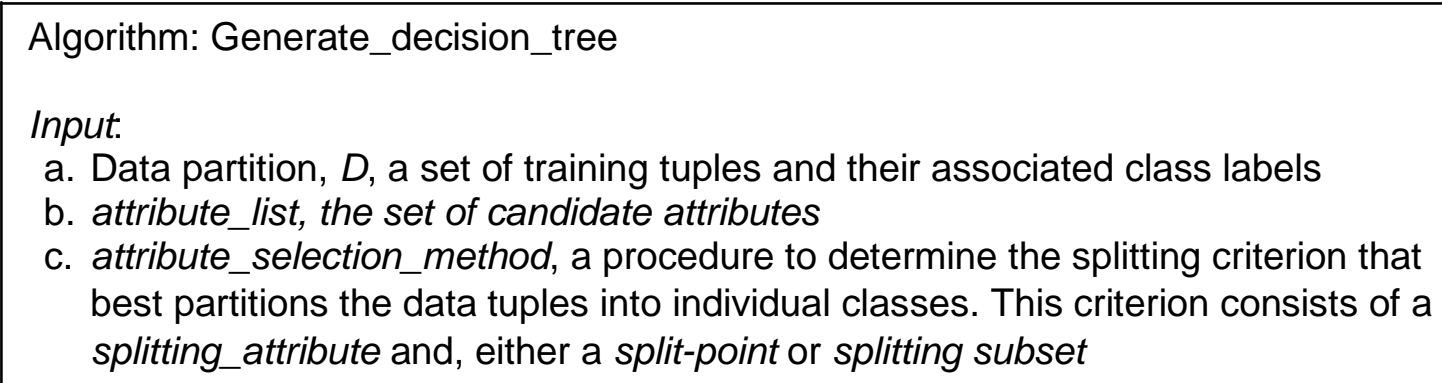

Output: a decision tree

Method:

1. create a node $N$

2. if tuples in $D$ are all of the same class, $C$, then

3. return $N$ as a leaf node labeled with the class $C$

4. if attribute_list is empty, then

5. return $N$ as a leaf node labeled with the majority class in $D$

6. apply attribute_selection_method ( $D$, attribute_list) to find the best splitting_criterion

7. label node $N$ with splitting_criterion

8. if splitting_attribute is discrete-valued and multiway splits allowed then

9. attribute_list $\leftarrow$ attribute_list - splitting_attribute

10. for each outcome $j$ of splitting_criterion

i. let $D j$ be the set of data tuples in $D$ satisfying outcome $j$

ii. if $D i$ is empty then attach a leaf labeled with majority class in $D$ to node $N$

iii. else, attach the node returned by Generate_decision_tree ( $D j$, attribute_list) to node $N$

11. return $N$

The classification model was evaluated by calculating accuracy. The accuracy indicates success rate of the model on testing data which is calculated based on number of data that are correctly predicted or not by the model. In addition to accuracy, precision and recall are used to evaluate the classification model.

$$
\text { Accuracy }=\frac{\text { number of correct classificatior }}{\text { total number of testing data }} \times 100 \%
$$

Precision dan recall are calculated based on the confusion matrix on Table 3.

Table 3. Confusion matrix

\begin{tabular}{ccc}
\hline & Predicted: Yes & Predicted: No \\
\hline Actual: Yes & $\mathrm{TP}$ & $\mathrm{FN}$ \\
Actual: No & $\mathrm{FP}$ & $\mathrm{TN}$ \\
\hline \multicolumn{3}{c}{ Precision $=\frac{\mathrm{TP}}{\mathrm{TP}+\mathrm{FP}}$} \\
\\
Recall $=\frac{\mathrm{TP}}{\mathrm{TP}+\mathrm{FN}}$
\end{tabular}




\section{RESULT AND DISCUSSION}

The C5.0 algorithm was applied on the datasets to result tree and rule-based models. Model evaluation was done using 10-cross validation. Accuracy of the tree model at each fold is shown in Figure 7.

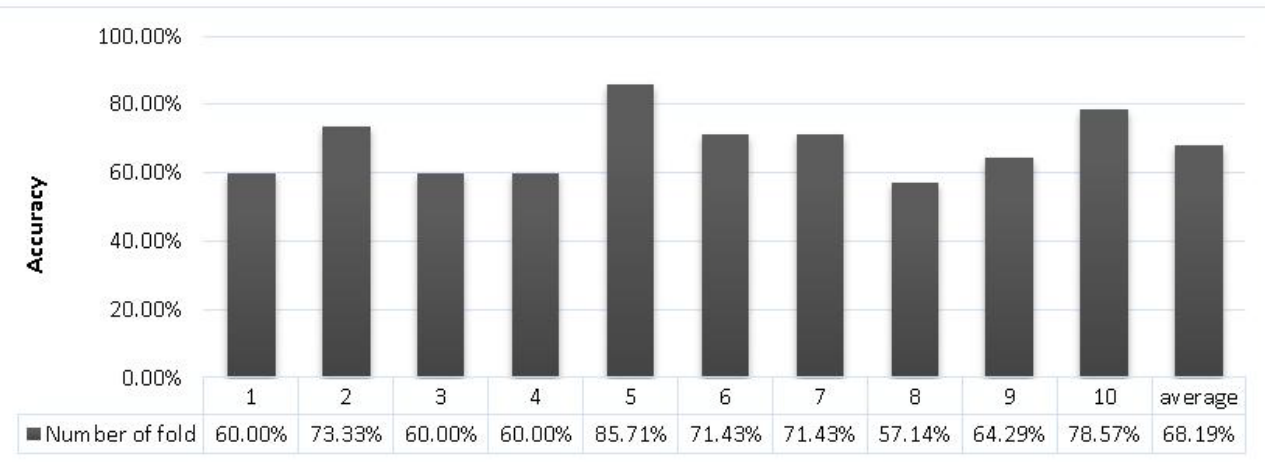

Figure 7. The accuracy of each fold

Based on Figure 7, the highest accuracy of tree model is obtained in the dataset at fold 5 that reach $85.71 \%$. The tree has the attribute course_module_view (V4) as the root as shown in Figure 8. It means that this attribute has most influence the final score of data mining course. According to the tree on Figure 8 , if $\mathrm{V} 4 \leq 1$ then as many 84 data are classified as the class C2 whereas if V4 $>1$ then as many 46 data are classified as the class $\mathrm{C} 1$. These rules indicate that students who frequently access the course module have the better final grade than students who never access the module or access the module only once. Students in the class label C1 have final grade $A$ and $A B$ whereas students in the class label $C 2$ have final grade $B$ and $\mathrm{BC}$ for Data Mining course. Table 4 provides the precision and recall of the model.

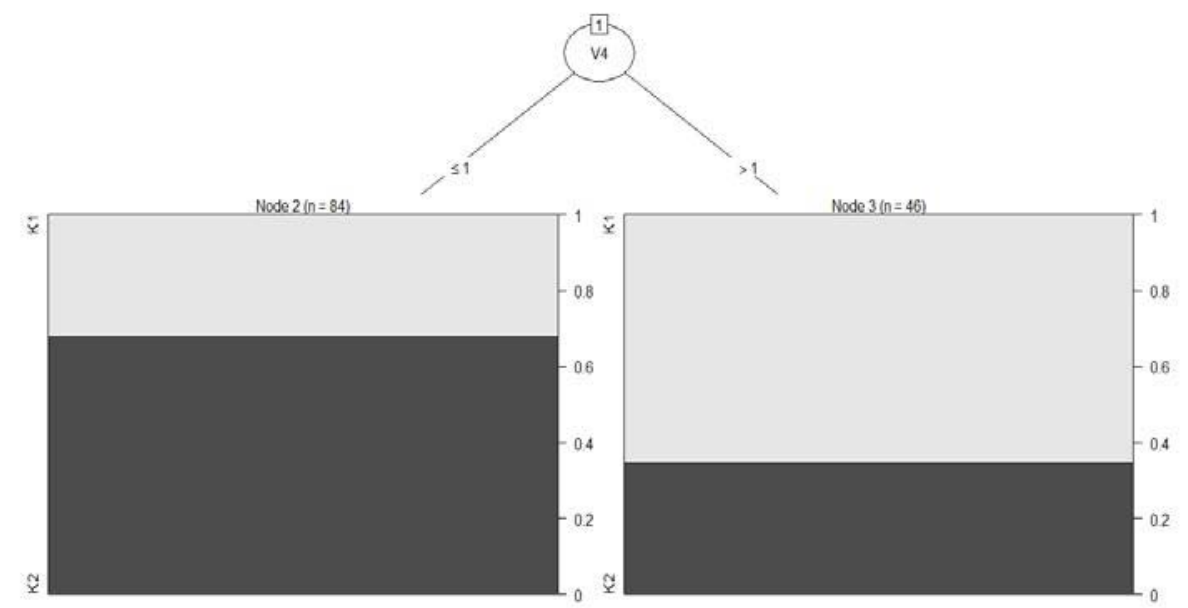

Figure 8. The decision tree with the best accuracy, precision and recall . 
Table 4. Precision and recall of the model

\begin{tabular}{crr}
\hline Class & Precision & \multicolumn{1}{c}{ Recall } \\
\hline C1 & $100 \%$ & $66.67 \%$ \\
C2 & $80 \%$ & $100 \%$ \\
\hline
\end{tabular}

According to Table 1, IPB-LMS log files for Data Mining course have four variables namely number of assignments done by students (n_assigment), number of views of data mining assignment ( $n_{-}$view_assigment), number of course view (n_course_view) and number of course module view (n_course_module_view). However, the tree model shows that only one variable that classify students into the class $C 1$ with final grade $A$ and $A B$ or the class $C 2$ with final grade $B$ and $B C$. Students' activities in viewing and submitting the assignment do not influence the students' performance on completing Data Mining course. Therefore, in further work teachers should evaluate the assignment module in IPB-LMS for Data Mining course so that students' activities in finishing the assignment in IPB-LMS influence the final grade of the course. In addition, future work is expected to involve larger datasets that are obtained from log files for several academic years. So that trend of students' activities in IPB-LMS for Data Mining course can be evaluated.

\section{CONCLUSION AND SUGGESTION}

This study has successfully developed decision tree-based classification model for IPB students' grade in Data Mining Course by involving students' activities in IPB Learning Management System (IPB-LMS). The best classification model has the accuracy of $85.71 \%$. The students' activities in IPB-LMS that provides high influence in Data Mining grade is course module view. Student's activity in accessing course modules in LMS represents how is student interesting in topics that discuss in the class room and computer laboratory. Course modules help students in understanding the material that will be examined in middle and final exams as well as final project evaluation. Therefore, student's activities in LMS represented by the parameter course module view will support student's achievement in Data Mining course in IPB. 


\section{REFERENCES}

\section{Books}

Han, J., Kamber, M., and Pei, J. (2012). Data Mining: Concepts and Techniques. 3rd ed. Massachusetts, US: Morgan Kaufmann.

\section{Journals/ Proceedings}

Ali Buldu, Kerem Üçgün. (2010). Data mining application on students' data. Procedia Social and Behavioral Sciences 2 (2010) pp. 5251-5259.

Amirah Mohamed Shahiri, Wahidah Husain, Nur'aini Abdul Rashid. (2015). A Review on Predicting Student's Performance using Data Mining Techniques. Procedia Computer Science 72 (2015) pp. 414 - 422.

Cristo'bal Romero, Sebastia'n Ventura, Enrique Garci'a. (2008). Data mining in course management systems: Moodle case study and tutorial. Computers \& Education 51 (2008) pp. 368-384

Cristóbal Romero, Sebastián Ventura, Amelia Zafra. (2009). Applying Web usage mining for personalizing hyperlinks in Web-based adaptive educational systems. Computers \& Education 53 (2009) pp. 828-840

Dewi Juliah Ratnaningsih \& Imas Sukaesih Sitanggang (2016) Comparative analysis of classification methods in determining non-active student characteristics in Indonesia Open University, Journal of Applied Statistics, 43:1, pp. 87-97,

Enrique García, Cristóbal Romero, Sebastián Ventura, Carlos de Castro. (2011). A collaborative educational association rule mining tool. Internet and Higher Education 14 (2011) pp. 77-88

Harwati, Ardita Permata Alfiani, Febriana Ayu Wulandari. (2015). Mapping Student's Performance Based on Data Mining Approach (A Case Study). Agriculture and Agricultural Science Procedia 3 (2015) pp. 173 - 177.

Leah P. Macfadyen, Shane Dawson. (2010). Mining LMS data to develop an "early warning system" for educators: A proof of concept. Computers \& Education 54 (2010) pp. 588-599.

Mohammed I.Al-Twijri, Amin Y. Noaman. (2015). A New Data Mining Model Adopted for Higher Institutions. Procedia Computer Science 65 (2015) pp. 836 - 844.

Parneet Kaur, Manpreet Singh, Gurpreet Singh Josan. (2015). Classification and prediction based data mining algorithms to predict slow learners in education sector. Procedia Computer Science 57 (2015) pp. 500 - 508.

Rulequest Research. (2018). Data Mining Tools See5 and C5.0. Retrieved November 2018 from http://www.rulequest.com/see5-info.html

Zailani Abdullah, Tutut Herawan, Noraziah Ahmad, Mustafa Mat Deris. (2011).

Extracting highly positive association rules from students' enrollment data.

Procedia - Social and Behavioral Sciences 28 (2011) pp. 107 - 111. 


\section{ABOUT THE AUTHORS}

Imas Sukaesih Sitanggang: Lecturer, Computer Science Department, Bogor Agricultural University, Bogor, Jawa Barat, Indonesia

Mutiara Santika: Student, Computer Science Department, Bogor Agricultural University, Bogor, Jawa Barat, Indonesia

Mayanda Mega Santoni: Lecturer, Faculty of Computer Science, UPN Veteran Jakarta, Jakarta Selatan, Indonesia 